\title{
INFANCIA EM MUDANÇA ROTINAS DE VIDA DE UM RAPAZ DE 10 ANOS DE ALCARIA (FUNDÃO)
}

\author{
António Faustino \\ Escola Superior de Educação do Instituto Politécnico de Castelo Branco \\ a.faustino@ipcb.pt \\ Daniel Ascensão \\ Escola Superior de Educação do Instituto Politécnico de Castelo Branco \\ daniel.ascensao@ipcbcampus.pt \\ Daniela Furtado \\ Escola Superior de Educação do Instituto Politécnico de Castelo Branco \\ d.furtado@ipcbcampus.pt \\ Helena Fernandes \\ Escola Superior de Educação do Instituto Politécnico de Castelo Branco \\ h.fernandes@ipcbcampus.pt \\ Inês Costa \\ Escola Superior de Educação do Instituto Politécnico de Castelo Branco \\ ines.costa2@ipcbcampus.pt \\ Rafael Freire \\ Escola Superior de Educacão do Instituto Politécnico de Castelo Branco \\ r.freire@ipcbcampus.pt
}

Recepción Artículo: 27 agosto 2021 Admisión Evaluación: 07 septiembre 2021 Informe Evaluador 1: 12 septiembre 2021 Informe Evaluador 2: 13 septiembre 2021 Aprobación Publicación: 15 septiembre 2021

\section{RESUMEN}

A investigação teve como objetivo caraterizar a rotina diária de um rapaz de 10 anos.

0 estudo baseou-se na realização de entrevistas narrativas e semiestruturadas com registo audiovisual, elaboração de mapas diários de ocupação temporal, registos fotográficos, assim como na execução de mapas subjetivos da habitação, rua e outros locais que frequenta, entrevistas de inventário dos objetos pessoais da criança e documentação fotográfica. Efetuámos ainda 0 devido acompanhamento nas suas tarefas quotidianas, pelos locais que habitualmente frequenta, durante uma semana. Os dados obtidos foram categorizados em função das atividades realizadas pela criança, seguindo-se uma análise ao tempo dedicado a cada atividade e categoria, tendo em conta os dias da semana, atividades que implicam movimento ou não, as ações realizadas dentro e fora de casa. Através da sua análise pode-se verificar que a criança em estudo vive com os seus pais e irmão, numa vivenda localizada numa quinta. A criança frequenta diariamente o ATL e pratica futsal. Esta criança, no seu Mundo Vivido despende muito tempo (todos os dias da semana de manhã e à tarde) em instituições (escola e 


\title{
INFANCIA EM MUDANÇA ROTINAS DE VIDA DE UM RAPAZ DE 10 ANOS DE ALCARIA (FUNDÃO)
}

ATL). 0 restante é passado em casa e no espaço envolvente. No que respeita ao Mundo do Movimento, passa a maior parte do tempo no quarto a jogar Playstation e a ver televisão.

Palabras clave: criança; rotinas de vida; plano de ocupação temporal semanal; entrevista do decurso do dia; mapa subjectivo; entrevista de inventário

\begin{abstract}
Changing Childhood. Routines of life of a 10 -year-old boy in Alcaria (Fundão).

The purpose of the investigation was to characterize the daily routine of a boy of 10 years. The study was based on narrative and semi-structured interviews with audiovisual record, elaboration of daily plans of temporal occupancy, photographic record, as well as charting subjective housing, streets and other places where she usually goes, inventory interviews of personal objects and photographic documentation of the child. We also followed up on his daily tasks, in the places he usually go, for a week. The data obtained were categorized according to the activities performed by the child, followed by an analysis of the time devoted to each activity and category, taking into account the days of the week, activities that involve movement or not, the actions performed inside and outside the home. Through their analysis, it can be concluded that the child under study lives with his parents and brother, in a house located on a farm. The child attends ATL daily and practices futsal. This child, in his Living World, spends a lot of time (every weekday morning and afternoon) in institutions (school and ATL). The rest is spent at home and in the surrounding space. As far as Movement World is concerned, he spends most of his time in his bedroom playing Playstation and watching TV.
\end{abstract}

Keywords: children; daily routine; life plan of week temporal occupancy; interview during the day; subjective map; interview of inventory

\section{INTRODUCCIÓN}

Embora atualmente pareça que o desenvolvimento da maioria das crianças está a decorrer de uma forma adequada, são diversos os comentários de investigadores, médicos e pedagogos que o caraterizam como falta de movimento, como revelando um aumento da fraqueza das condutas motoras, da sua falta e até mesmo uma perda, dos sentidos.

A sociedade em que vivemos é uma sociedade em mudança. A súbita industrialização, o avanço tecnológico, conduziram ao desenvolvimento de centros urbanos que condicionam o dia-a-dia de todos nós, levando-nos a uma vida cada vez mais sedentária.

Este fato reflete-se com notoriedade na vida das crianças, por natureza espontaneamente ativas, levando-as a substituir 0 correr, 0 saltar, (...) pelo consumo excessivo de televisão e jogos electrónicos (Astrand, 1994; Bijnen et coll. 1994).

Face a isto, acredita-se que a atividade física das crianças possa vir a sofrer uma diminuição progressiva, podendo conduzir a um esquecimento que a mesma assume no desenvolvimento moral, social, intelectual e motor da criança (Neto, 1994).

Segundo Graue \& Walsh (2003: 17) «a bibliografia relacionada com as crianças mais pequenas está repleta de estudos em que as crianças foram objecto de escrutínio. É, por isso, surpreendente que, existindo tantos trabalhos centrados nas crianças, saibamos tão pouco acerca das suas vidas. Pouca ou nenhuma atenção é prestada aos contextos em que as crianças se movem.» Os mesmos autores consideram que os contextos das crianças mudaram radicalmente nos últimos anos à medida que os fatores sociais, culturais e económicos modificaram os recursos e as ferramentas das suas vidas. Por contexto entendem «um espaço e um tempo cultural e historicamente situado, um aqui e agora especifico» (2003: 24-25).

Caraterizar as rotinas de vida diária percebendo se, o meio ambiente que envolve as crianças implica movimento, entender 0 mundo através da perspetiva da criança, conhecer os objetos com que as crianças passam 0 seu tempo, entender o mundo numa retrospetiva pessoal das crianças, são elementos indispensáveis a fim de se obter uma perceção da vida diária das crianças. 
Nos dias de hoje, parece incontestável o contributo da atividade física regular na promoção de um estilo de vida ativo e na criação de hábitos de exercício. Partindo assim do pressuposto de que a atividade física contribui para a obtenção de hábitos de vida saudável provocando uma melhoria no ser humano a diversos níveis, tais como a saúde, o bem-estar físico, mental e social, foram vários os autores que procuraram contribuir para a sua definição (Caspersen, Powell \& Christenson, 1985; Haskell, Montoye \& Orenstein, 1985; Wold \& Anderssen, 1992; Bouchard e col.,1993; Mota, 1993; Bouchard \& Shephard, 1994; Pols, 1996; Maia, 1997).

Nos últimos anos, vários estudos (Duarte, 1991; Cale, 1992; Gonçalves, Monteiro, Ghirotto \& Júnior, 1994; Serrano, 1996; Costa, 1997; Gomes, 1997) foram desenvolvidos sobre a atividade física das crianças.

Para completar a fundamentação da investigação recorremos ainda a estudos similares, realizados por Faustino, Mesquita, Pissarra, Serrano, Barata, Mariano \& Silva (1995), Faustino, Mesquita, Pissarra, Serrano, Riscado, Lourinho \& Sequeira (1995), Faustino, Mesquita, Pissarra, Serrano, Roupa, Gonçalves \& Lopes (1995), Faustino, Gomes, Freches, Dias, Roque \& Fialho (2008), Faustino, Fernandes, Correia, Salgueiro, Botas \& Martins (2008), Faustino, Rosado, Rodrigues, Silva, Vide \& Gomes (2008), Faustino, Campos, Colhe, Seco \& Proença (2009), Faustino, Cunha, Jacinto, Balona \& Pedroso (2009), Faustino, Mariano, Teixeira \& Gomes (2009), Faustino, Monteiro \& Gonçalves (2009).

\section{OBJETIVOS DE LA INVESTIGACIÓN}

Propomo-nos prestar um contributo para uma caraterização das rotinas de vida diária das crianças, pretendendo-se verificar: que tipo de tarefas realizam no seu dia-a-dia; de que forma ocupam o seu tempo e como 0 gerem na realização das suas tarefas diárias; qual o seu grau de autonomia de mobilidade; quais os locais que têm como hábito frequentar no dia-a-dia; que perceção têm do espaço onde se deslocam para realizar as suas atividades; como estabelecem as suas relações interpessoais e como interpretam o seu curso de vida.

É intenção do estudo procurar dar resposta aos seguintes objetivos: 1- Caraterizar as atividades que realiza no seu quotidiano. 2- Comparar as atividades realizadas nos dias de semana com as realizadas no fim-de-semana. 3-Comparar as atividades realizadas dentro e fora de casa. 4- Analisar o grau de autonomia de mobilidade no espaço em que desenvolve as atividades semanais. 5- Comparar as atividades realizadas sozinha e acompanhada. 6- Comparar as atividades realizadas com e sem mobilidade. 7- Analisar os factos significativos que marcaram o seu percurso de vida.

\section{MUESTRA Y/O PARTICIPANTES}

Segundo Flick (2005: 73) «o caso representa-se a si próprio», a que acrescenta adiante «o caso representa uma subjectividade desenvolvida em resultado da aquisição de determinados volumes de conhecimento e da evolução de modos específicos de acção e percepção».

A criança escolhida para o estudo é do sexo masculino com a idade de 10 anos, residente em Alcaria, uma aldeia do concelho do Fundão.

\section{METODOLOGÍA Y/O INSTRUMENTOS UTILIZADOS}

Face às questões enunciadas e aos objetivos do nosso estudo, procedemos a uma abordagem por triangulação, que consiste na «utilização de diferentes métodos combinados, no interior do mesmo estudo» (Reidy \& Mercier, 2000: 322). Serve para comparar dados obtidos com a ajuda de vários processos num mesmo estudo. De acordo com as mesmas autoras, a triangulação tipo é aquela em que se « reúnem métodos qualitativos e quantitativos» (ibidem).

Contudo, na nossa investigação, para além de triangulação de métodos, também utilizamos a triangulação dos dados, que consiste numa colheita de dados « junto de diversas fontes de informação. . . a fim de estudar um mesmo fenómeno» (Reidy \& Mercier, 2000: 323). 


\section{INFANCIA EM MUDANÇA ROTINAS DE VIDA DE UM RAPAZ DE 10 ANOS DE ALCARIA (FUNDÃO)}

Apesar de utilizarmos a triangulação, é fundamental explicitar que partimos de uma perspetiva fenomenológica. No entender de Bogdan \& Biklen (1994), 0 investigador fenomenologista procura compreender o significado que os acontecimentos têm para pessoas vulgares, em contextos particulares.

Para o desenvolvimento da investigação foi necessário utilizar vários instrumentos de recolha de dados, uma vez que se pretende recolher informação relativa ao tempo despendido pela criança em cada atividade por si realizada.

No sentido de encontrarmos quer as pistas orientadoras para esta pesquisa, quer os contributos para a definição do quadro teórico de referência, recorremos às entrevistas narrativas, às entrevistas semi-estruturadas, que têm «como função principal revelar determinados aspectos do fenómeno ...., completar as pistas de trabalho sugeridas pelas suas leituras» (Quivy \& Campenhoudt, 1998: 69). A aplicação de uma entrevista narrativa semiestruturada prende-se com o facto de se pretender recolher informações sobre o tempo do dia todo, que complemente a informação em função das ações que facilitam ou coibem, onde decorrem, com quem, o quê, como.

Este instrumento permite-nos a obtenção de dados no âmbito de 3 domínios:

I- Conhecer 0 que está a criança a fazer?

II- Saber quanto tempo está a criança a fazer determinada coisa?

III- Saber onde está a criança a fazer algo (dentro ou fora da habitação)?

É composta por questões abertas, estas estão menos sujeitas à influência do investigador, permitindo uma maior veracidade, uma vez que favorecem a livre expressão, sendo também úteis para explicitar as perguntas fechadas (Pardo de Velez, 1997).

Utilizámos ainda a entrevista narrativa e a semi-estruturada sobre os acontecimentos da vida, métodos cujo objetivo é obter mais conhecimento biográfico para conhecer melhor a criança.

0 objetivo da entrevista narrativa é dar ao narrador a oportunidade de falar sobre a sua própria vida, numa ordem e com núcleos de decisão própria. Quando o narrador paira ou não sabe mais o que falar, deve-se passar para uma entrevista semi-estruturada.

Com este tipo de entrevista devem-se questionar os âmbitos do curriculum vitae infantil que não foram mencionados na narrativa. A entrevista semi-estruturada, constitui um instrumento privilegiado na investigação qualitativa, nomeadamente na de cariz fenomenológica, pois como afirmam Fortin, Grenier \& Nadeau (2000: 247) «0 respondente cria as suas respostas e exprime-as pelas suas próprias palavras». De acordo com Fortin, Grenier \& Nadeau (ibidem), nas entrevistas semi-estruturadas utiliza-se « um guião com as grandes linhas dos temas a explorar's.

A escolha e a formulação das perguntas orientam-se pelo quadro teórico do projeto - a vida de movimento das crianças, pelo que se construiu um guião que serviu de referência à condução das entrevistas, por forma a obter dados no âmbito de 4 domínios:

A) Dos itens - tempo e espaço.

- «Gostas de ser responsável pela organização (de ser autónomo) do teu tempo ou preferes as horas marcadas?»

- «Gostas mais de jogar dentro ou fora de casa? Porquê?»

- «0 que é que tu e os teus amigos fazem dentro de casa? Porquê?»

- «0 que é que tu e os teus amigos fazem fora de casa? Porquê?»

B) Do relacionamento com o bairro.

- «Gostas da tua casa? Porquê?»

- «Gostas do bairro onde moras? Porquê?»

C) Do eu e do meu próprio corpo.

- «Gostas de jogos em que precisas de usar o teu corpo? Porquê?»

- «Gostas de jogos em que tenhas de te movimentar? Porquê?»

- «Gostas de jogos em que uses a força corporal? Porquê?» 
- «Se não gostas, porque é que não gostas, quais as razões?»

D) Do corpo social (eu e os meus amigos).

- «Como é que te vês em relação aos teus amigos? Vizinhos? Colegas da escola? Colegas do clube?»

\section{Procedimentos}

Estabeleceu-se um contacto prévio com a família da criança a fim de lhe pedir a sua colaboração e explicar os objetivos do estudo. Após a família revelar vontade em participar procedeu-se à marcação das entrevistas. Estas foram gravadas em vídeo com a devida autorização e disponibilidade do participante.

Iniciámos o estudo com a recolha do plano diário de ocupação temporal, completado com uma entrevista narrativa semiestruturada sobre o tempo do dia todo, tendo sido estas aplicadas pelo estudante/investigador familiar da criança. A primeira entrevista foi realizada no domicílio da criança, no dia 07/05/2021, com a duração aproximada de $2 \mathrm{~h} 30$. A segunda entrevista, levada a cabo na casa do entrevistador, foi no dia 18/05/2021 e durou 4 h00.

Concluída a execução de cada uma delas, procedeu-se à audição integral e respetiva transcrição. Posteriormente fez-se a análise através da técnica de análise de conteúdo, tendo assim emergido blocos temáticos.

Em ambas as entrevistas sobre o desenho, a criança foi solicitada para desenhar os lugares que têm um significado no seu mundo de vida. Optou por desenhar a sua casa e o espaço envolvente. No decorrer das duas entrevistas, procedeu-se à entrevista fotográfica. Na primeira, o entrevistador acompanhou a criança pela quinta de residência, para fotografar a casa e o espaço envolvente. Na segunda entrevista, ambos se deslocaram ao Fundão para fotografar a escola e o pátio, seguindo posteriormente, para o Dominguizo, para fotografar o paviIhão onde se realizam os treinos de futsal.

Em todos os momentos, aquando da recolha de dados, foi assegurado ao participante a confidencialidade das respostas, é «importante garantir aos potenciais sujeitos a confidencialidade das informações» (Fortin, Brisson \& Coutu-Wakulcayk, 2000: 122).

Deve-se «Aceitar as decisões da criança», «não forçando a situação». Deve-se deixar falar, mas sem fugir do tema, se interrompe talvez seja necessário outro impulso, mas sem mudar o tema.

\section{RESULTADOS ALCANZADOS}

Após a organização dos dados foram realizadas leituras repetidas do texto das entrevistas, a fim de estabelecer contato com as narrativas do sujeito e conhecer o texto, como diz Bardin (2000: 96) «deixando-se invadir por impressões e orientações». Dubouloz (2000: 316) acrescenta que esta fase serve para «entrar no contexto do texto familiarizando-se com a experiência relatada..., de forma a descobrir nele o sentido global’s.

As questões de codificação são pertinentes no decorrer de uma análise de conteúdo. Assim, o sistema de codificação passou pela escolha das categorias, facilitando, deste modo, uma arrumação sintética e significante do conteúdo dos discursos. Vala (1986: 110) afirma que as «categorias são os elementos-chave do código do analistas.

Nesta investigação optou-se por construir as categorias a posteriori. Esta decisão é corroborada por Vala (1986: 111) quando afirma que «a construção de um sistema de categorias pode ser feita a priori ou a posteriori, ou ainda através da combinação destes dois processos"».

Uma vez construídas as categorias, passámos à identificação das subcategorias existentes, tendo-se procedido à identificação das unidades de registo, que para Vala (1986: 114) é 0 «segmento determinado de conteúdo que se caracteriza colocando-o numa determinada categoria». É de salientar que são os objetivos e a problemática da investigação que determinam a natureza das unidades a utilizar. Para uma melhor interpretação dos dados relativos às atividades diárias houve necessidade de agrupar algumas atividades. Deste modo num primeiro momento consideramos:

- Atividades escolares: momentos do dia em que a criança está na escola, é de distinguir o tempo de recreio e as aulas de Expressão Físico-Motora / Educação Física (implicam mobilidade), das restantes aulas (que não 


\section{INFANCIA EM MUDANÇA ROTINAS DE VIDA DE UM RAPAZ DE 10 ANOS DE ALCARIA (FUNDÃO)}

pressupõem mobilidade, a criança permanece sentada), bem como a realização dos trabalhos de casa e o tempo despendido a estudar.

- Atividades domésticas: aquelas que executa dentro de casa, na ajuda das tarefas domésticas, como limpar a casa, arrumar a cozinha, fazer a cama.

- Refeições: momentos do dia em que prepara as refeições (pequeno-almoço, almoço, lanche, jantar) e se alimenta.

- Atividades desportivas: aquelas praticadas num clube, associação, etc.

- Atividades lúdicas ou televisivas: aquelas atividades de divertimento que pratica sozinha ou acompanhada, em casa ou na rua. Momento do dia em que assiste a programas nos canais televisivos.

- Atividades de mobilidade: aquelas que implicam deslocações efetuadas na rua.

- Atividades de lazer: outras ocupações que realiza (rezar, ler livros ou jornais, conversar com familiares).

- Atividades de higiene pessoal: aquelas que implicam limpeza e cuidado pessoal (ex: lavar os dentes, tomar banho).

- Dormir: tempo despendido em descanso e repouso pessoal.

- Outras: aqueles momentos ou tarefas que não se incluem nas restantes categorias.

Os dados provenientes da observação foram tratados em computador com a ajuda de software (Microsoft Excel 97 SR-1 - Microsoft Corporation).

Utilizou-se uma análise descritiva, pelo que os dados de caraterização do sujeito são apresentados na sua expressão de trabalho (percentagem) e as conclusões, em função dos objetivos de estudo formulados.

A fórmula adotada para calcular as percentagens foi a seguinte:

$$
\frac{\text { Número de horas da atividade x } 100}{\text { Número de horas total }}
$$

Os resultados são apresentados e discutidos respeitando a seguinte ordem:

\section{Atividades semanais}

Durante a semana, a criança tem bastantes atividades e variadas (ver gráfico 1). A maior parte do tempo é despendido a dormir (29\%), seguindo-se as atividades escolares (26\%), divididas entre a escola e o ATL. Depois, destacam-se as atividades lúdicas (24\%), que realiza nos intervalos da escola e no ATL em brincadeiras com os amigos, mas também a ver televisão ou a jogar Playstation, em casa. 0 restante tempo é dividido por atividades de mobilidade, refeições, higiene pessoal, atividades desportivas ou outras atividades, tais como vestir-se ou levantar-se da cama. Não realiza atividades domésticas ou de lazer.

Gráfico 1: Atividades durante a semana.

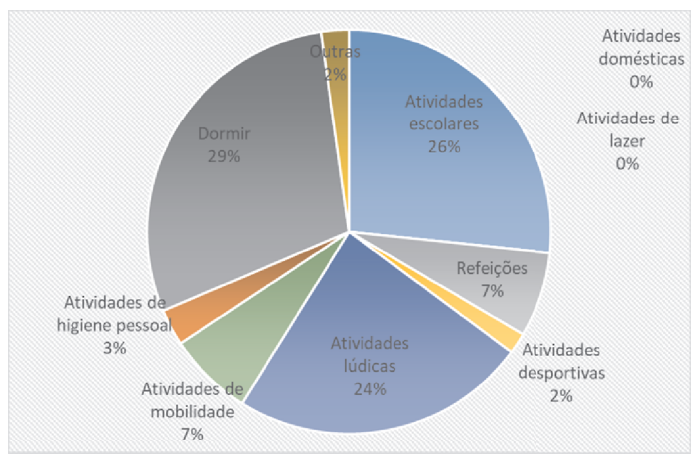




\section{Atividades ao fim-de-semana}

Numa análise ao fim-de-semana (ver gráfico 2), é possível observar que a maior parte do tempo é dedicado às atividades lúdicas (49,65\%), tais como ver televisão ou jogar Playstation e brincar com o irmão. Dormir também ocupa grande parte do horário (35,42\%), sendo que, o restante se divide em atividades de higiene pessoal, refeições ou outras. Ao fim de semana não tem atividades escolares, desportivas ou de mobilidade. Tal como durante a semana, não realiza atividades domésticas ou de lazer.

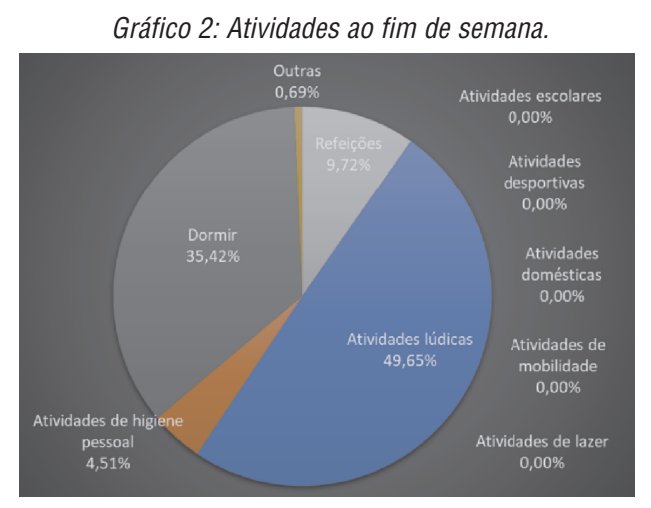

\section{Análise comparativa entre os dias durante a semana versus o fim-de-semana}

Fazendo a análise comparativa dos dados dos gráficos 1 e 2, podem-se verificar as diferenças que existem entre as atividades realizadas semanalmente e as atividades durante 0 fim-de-semana.

Começando pela higiene pessoal, despende 210 minutos na semana e 130 minutos no fim-de-semana. 0 que revela que durante a semana ocupa uma média de 42 minutos diários para higiene, e no fim-de-semana ocupa 65 minutos diários.

Em relação às refeições gasta 490 minutos durante a semana, ao passo que, no fim-de-semana 280 minutos. Deste modo, concluímos que o tempo médio diário gasto para as refeições é inferior durante a semana em relação ao fim-de-semana.

Relativamente a atividades desportivas, a criança ocupa 120 minutos na semana na prática de futsal, não tendo qualquer tempo despendido nestas atividades no fim-de-semana.

As atividades escolares, ocupam $26,67 \%$ do seu tempo durante a semana, não ocupando percentagem alguma ao sábado ou domingo.

Durante o fim-de-semana, com exceção do tempo que passa a dormir, as atividades lúdicas com 1430 minutos são as que ocupam a maior parte do seu tempo, ao passo que durante a semana despende 1710 minutos nestas atividades. Considerando o que considerámos atividades lúdicas concluímos que durante 0 fim-de-semana a criança aproveita para brincar mais tempo ao ar livre, aproveitando o espaço envolvente da habitação.

Comparando 0 tempo gasto a dormir, verificamos que durante a semana a criança dorme uma média de 420 minutos por dia, enquanto no fim-de-semana despende 510 minutos diários.

Por último, a criança só gasta tempo em atividades de mobilidade durante a semana, permanecendo em casa durante o fim-de-semana. Não despende qualquer tempo em atividades domésticas nem em atividades de lazer.

\section{Análise das atividades com e sem movimento}

Considerando como atividades com movimento as atividades desportivas, os intervalos na escola, as brincadeiras no ATL e com o irmão, verificamos que a criança tem muito pouca atividade com movimento. 


\section{INFANCIA EM MUDANÇA ROTINAS DE VIDA DE UM RAPAZ DE 10 ANOS DE ALCARIA (FUNDÃO)}

Gráfico 3: Comparação das atividades com e sem movimento.

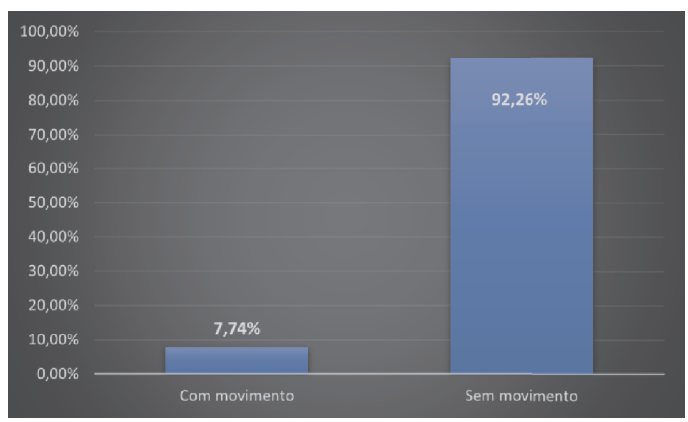

Nas atividades sem movimento incluem-se: as atividades escolares, seja na escola ou no ATL; as atividades de mobilidade, pois desloca-se sempre de carro ou autocarro e permanece sentado; as atividades lúdicas (ver televisão ou jogar Playstation); as refeições; a higiene pessoal; 0 tempo despendido a dormir; e outras atividades, não englobadas nas categorias anteriores. Através do gráfico 3, concluímos que as atividades sem movimento são muito superiores às atividades com movimento.

\section{Atividades desenvolvidas pela criança com ou sem acompanhamento}

As atividades que a criança realiza com acompanhamento englobam as atividades de mobilidade com o pai, as atividades escolares, na escola e no ATL, as atividades desportivas, as refeições e as atividades lúdicas realizadas com 0 irmão.

As atividades sem acompanhamento dizem respeito às restantes atividades de mobilidade e lúdicas, às atividades de higiene pessoal, ao tempo dedicado ao sono e a outras atividades.

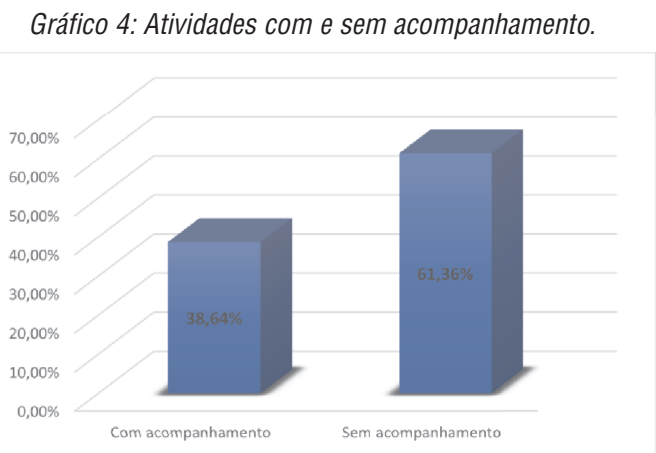

Da análise ao gráfico 4, é possível verificar uma discrepância nas atividades com e sem acompanhamento, sendo que a criança realiza mais atividades sozinha que acompanhada.

\section{Análise da entrevista de inventário}

A criança possui alguns brinquedos/jogos tais como: Playstation, computador, carros de brincar, cartas, Monopólio, "Quem é quem?", Legos, "4 em linha". Tem como preferência jogar Playstation ou computador. Nos intervalos da escola ou em casa, com os amigos e 0 irmão, costuma também jogar "à apanhada", "macaca", "macaquinho do chinês", "escondidas", saltar à corda, tiro ao alvo, jogar à bola ou ao "jogo do mata". 


\section{Análise do mapa subjetivo/objetivo}

No que diz respeito aos desenhos da criança, considerámos os desenhos da casa e espaço envolvente e os trajetos casa-escola e casa-pavilhão.

Quanto à casa e espaço envolvente, a criança tem noção da casa no exterior, tendo alguma dificuldade para desenhar a dimensão espacial do interior da habitação. Apesar disso, a localização das divisões está correta. Já o espaço envolvente, apresenta as duas habitações da quinta, bem como o pomar e a barragem.

Figura 1: (a) Desenho da habitação vista do exterior; (b) Desenho do interior da habitação; (c) Desenho da quinta.

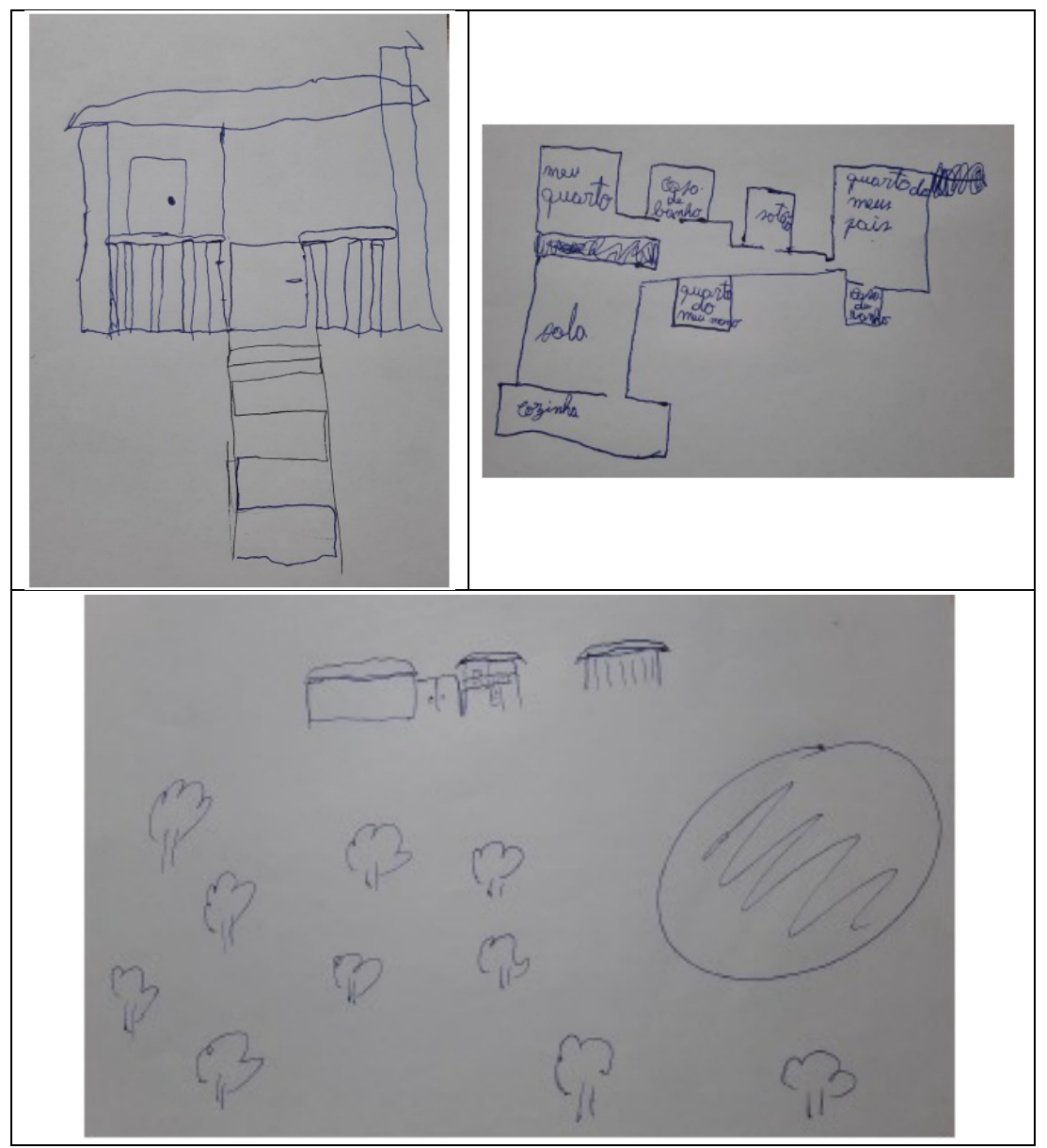

Tal como os desenhos da habitação, o trajeto casa-escola foi difícil de desenhar porque o percurso é longo, passando por várias rotundas e pontes. Ainda assim, a criança tem essa perceção, tendo desenhado três rotundas e uma ponte. 0 mesmo aconteceu com o trajeto casa-pavilhão: trajeto longo, mas perceção das rotundas e pontes. 


\section{INFANCIA EM MUDANÇA ROTINAS DE VIDA DE UM RAPAZ DE 10 ANOS DE ALCARIA (FUNDÃO)}

Figura a: (a) Desenho do trajeto casa-escola; (b) Mapa real do trajeto casa-escola; (c) Desenho do trajeto casa-pavilhão; (d) Mapa real do trajeto casa-pavilhão.
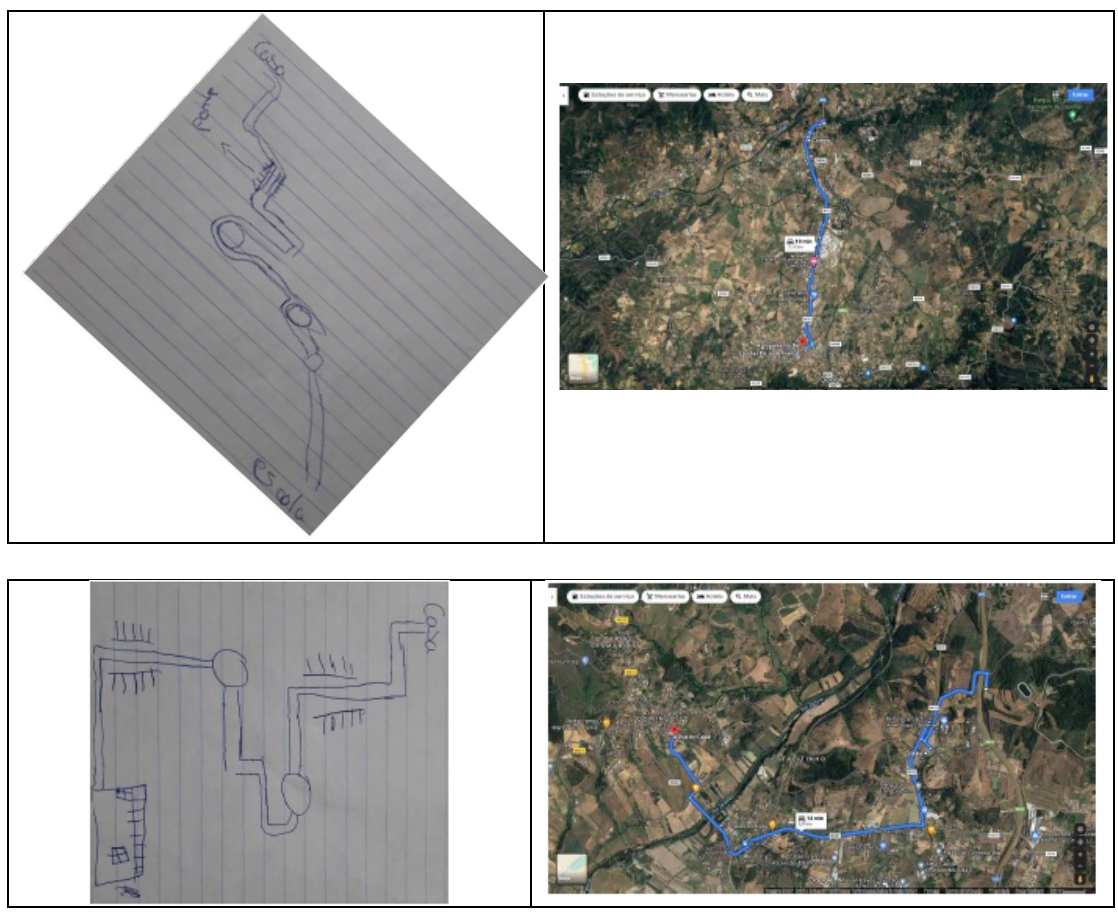

\section{Análise de entrevista narrativa e semiestruturada}

Nas entrevistas realizadas, a criança não revelou dados significativos da sua vida, acabando por se referir a que: - gosta muito da casa onde mora porque é grande, tem espaço para brincar e jogar;

- dentro de casa gosta de jogar Playstation, cartas, jogos de tabuleiro. Fora de casa, gosta de andar de bicicleta, jogar futsal, à apanhada e escondidas;

- gosta de jogos onde tenha de correr ou usar a força corporal;

- o seu desporto favorito é o futsal, modalidade que pratica.

Numa análise mais detalhada das entrevistas, a criança considera-se muito autónoma e com boa mobilidade. Para a gestão do seu tempo prefere ter horas marcadas, a ser o responsável pela organização do seu tempo. A sua preferência de local para jogar é fora de casa porque gosta de correr e saltar. Gosta muito da sua casa e do espaço envolvente porque tem muito espaço para brincar e porque 0 avô mora ao lado e adora passear pela quinta com ele. Além disso, pode levar lá muitos amigos. Na escola também gosta de jogar "à apanhada" e "às escondidas" nos intervalos, ocasionalmente aproveita para comer. Não jogam à bola porque não têm tempo, considera que os intervalos são pequenos.

\section{DISCUSIÓN}

Ao analisar as atividades desenvolvidas pela criança durante a semana, podemos observar que passa grande parte do seu tempo a dormir (29\%), destacando-se, seguidamente, as atividades escolares (26\%) e lúdicas $(24 \%)$. 
Relativamente às atividades realizadas ao fim-de-semana, podemos ver um aumento do tempo passado a dormir (35,42\%) e um aumento considerável das atividades lúdicas (49,65\%). 0 mesmo acontece com o tempo despendido nas refeições, sendo maior ao fim-de-semana que durante a semana. Tal deve-se a estar mais tempo em casa e passar mais tempo com a família à mesa.

Na semana analisada, tendo em conta as atividades com ou sem movimento, os dados sugerem estarmos face a uma criança que aparenta ter traços sedentários. Contudo, e devido a todo o espaço envolvente à casa, a criança aproveita muitas vezes o exterior para brincar, incluindo correr, saltar, jogar à bola, entre outras.

Em relação ao nível de dependência, a criança realiza muitas atividades sem acompanhamento. E das que realiza com acompanhamento, algumas não está dependente de outras pessoas, p.e., na hora das refeições é autónomo para comer, não necessitando da ajuda dos pais.

Estes dados sugerem estarmos face a uma criança pouco dependente e que permanece em duas instituições durante os dias de semana. Com exceção das atividades desportivas o restante tempo permanece em casa, principalmente no quarto.

\section{CONCLUSIONES}

0 presente trabalho teve como objetivo caracterizar as rotinas diárias de uma criança.

A recolha de dados foi complexa pois a criança mostrou pouco interesse e não levou as entrevistas muito a sério. Foi por isso necessário recolher dados mais precisos junto dos pais.

A criança demonstra grande evolução a nível tecnológico, principalmente nas brincadeiras online com os amigos. Apresenta traços sedentários pois passa muito tempo a jogar consola ou a ver televisão.

Com base na análise dos dados é possível afirmar que a criança estudada tem mais atividades sem que atividades com movimento. Apesar de ter prática desportiva, num clube de futsal, o tempo despendido nessa atividade é relativamente baixo, não por culpa da criança, mas devido à pandemia de covid-19, pois foram reduzidas as horas de treino e ao fim-de-semana não teve competições, por as competições de escalões etários mais baixos estarem suspensas. Pelo mesmo motivo também não teve aulas de educação física.

Contudo, é um rapaz que não rejeita atividades com movimento, adorando, por exemplo, passear pela quinta com 0 avô. Ocasionalmente, também costuma brincar ao ar livre com os amigos, no espaço envolvente à habitação, ou seja, na quinta.

\section{REFERENCIAS BIBLIOGRÁFICAS}

- ASTRAND, P.O. (1994). Physical activity and fitness: Evolutionary perspective and trends for the future. In: C. Bouchard, R.J. Shepard \& T. Stephens (Eds.) Physical activity, fitness, and health: International proceedings and consensus statement. Human Kinetics, Champaign, Illinois: 98-105.

- BANIK, B.J. (1993). Applying triangulation in nursing research. Applied Nursing Research, 6 (1): 47-54.

- BARDIN, Laurence (1988). Análise de conteúdo. Lisboa, Edições 70.

- BIJNEN, F.C.H. et coll. (1994). Physical inactive as is risk factor for coronary heart disease: A WHO and international Society and Federation of Cardiology position statement. Bulletin of the World Health Organization, 72 (1): 1-4.

- BOGDAN, Robert \& BIKLEN, Sari (1994). Investigação qualitativa em educação: uma introdução à teoria e aos métodos. Porto Editora, Porto.

- BOUCHARD, C. e col. (1993). The Consensus Statement. In: Bouchard, C. e col. (Eds.). Physical activity, fitness and heealth: international proceeding and consensos statement. Human Kinetics Publissshers, Inc. Champaign, Illinois.

- BOUCHARD, C. \& SHEPARD, R.J. (1994). Physical activity, fitness, and health: The model and key concepts. In: C. Bouchard, R.J. Shepard \& T. Stephens (Eds.) Physical activity, fitness, and health: International proceedings and consensus statement. Human Kinetics, Champaign, Illinois: 77-88. 


\section{INFANCIA EM MUDANÇA ROTINAS DE VIDA DE UM RAPAZ DE 10 ANOS DE ALCARIA (FUNDÃO)}

- CALE, L. (1992). Les enfants et l'inactivité, quelques explications possibles. Revue de l'Éducation Physique, 32 (1): 37-41.

- CASPERSEN, C., POWELL, K. \& CHRISTENSON, G. (1985). Physical activity, exercise and physical fitness. Definitions for Health-Related Research. Public Health Reports, 100 (2): 126-131.

- DUBOULOZ, Claire-Jehanne (2000). Métodos de análise dos dados em investigação qualitativa. In: MarieFabienne Fortin. 0 processo de investigação: da concepção à realização. Lusociência, Loures. 2. ${ }^{a}$ ed.: $305-$ 320.

- FAUSTINO, A., MESQUITA, M.H., PISSARRA, S., SERRANO, J., BARATA, Ana Margarida, MARIANO, António Carlos \& SILVA, Nelsa Maria (1995). Rotinas de Vida Diária de Crianças em Idade Escolar - Estudo de Caso (Rapaz - 9A). Trabalho da Disciplina de Desenvolvimento Motor. Castelo Branco, Escola Superior de Educação.

- FAUSTINO, A., MESQUITA, M.H., PISSARRA, S., SERRANO, J., CEREJO, Ana Paula, SOARES, Maria Manuela \& FERRO, João Carlos (1995). Rotinas de Vida Diária - Estudo de Caso (Rapariga - 10A). Trabalho da Disciplina de Desenvolvimento Motor. Castelo Branco, Escola Superior de Educação.

- FAUSTINO, A., MESQUITA, M.H., PISSARRA, S., SERRANO, J., RISCADO, Armando Luís, LOURINHO, Nuno Miguel \& SEQUEIRA, Paulo Jorge (1995). Rotinas de Vida Diária de uma Criança - Estudo de Caso (Rapaz - 9A). Trabalho da Disciplina de Desenvolvimento Motor. Castelo Branco, Escola Superior de Educação.

- FAUSTINO, A., MESQUITA, M.H., PISSARRA, S., SERRANO, J., ROUPA, José Manuel, GONÇALVES, Júlio Miguel \& LOPES, Paulo Fernando (1995). Rotinas de Vida de Uma Criança de Castelo Branco - Estudo Caso (Rapaz - 10A). Trabalho da Disciplina de Desenvolvimento Motor. Castelo Branco, Escola Superior de Educação.

- FAUSTINO, A. GOMES, Ana, FRECHES, Cristina, DIAS, Mariana, ROQUE, \& FIALH0, Tiago (2008). Caracterização das Rotinas de Vida Diária de Crianças de Castelo Branco - Estudo de caso: criança de 9 anos residente em Castelo Branco. Trabalho da Unidade Curricular de Desenvolvimento Motor. Castelo Branco, Escola Superior de Educação.

- FAUSTIINO, A., FERNANDES, André, CORREIA, Bruno, SALGUEIRO, Francisco, BOTAS, João \& MARTINS, Vanessa (2008). Caracterização das Rotinas de Vida Diária de Crianças de Castelo Branco - Estudo de caso (Rapaz 8 A). Trabalho da Unidade Curricular de Desenvolvimento Motor. Castelo Branco, Escola Superior de Educação.

- FAUSTINO, A., ROSAD0, Diogo, RODRIGUES, Flávio, SILVA, Jean, VIDE, José \& GOMES, Samuel (2008). Caracterização das Rotinas de Vida Diária de Crianças de Castelo Branco - Estudo de um caso: Criança de 8 anos. Trabalho da Unidade Curricular de Desenvolvimento Motor. Castelo Branco, Escola Superior de Educação.

- FAUSTINO, A., CAMPOS, Andreia, COLHE, Rodolfo, SECO, Rodrigo \& PROENÇA, Verónica (2009). Caraterização da rotina diária de uma criança de 9 anos residente em Alpiarça. Trabalho da Unidade Curricular de Desenvolvimento Motor. Castelo Branco, Escola Superior de Educação.

- FAUSTINO, A., CUNHA, André, JACINTO, Daniel, BALONAS, Hélder \& PEDROSO, Paulo (2009). Caraterização das rotinas de vida de uma criança de 8 anos - Estudo de caso. Trabalho da Unidade Curricular de Desenvolvimento Motor. Castelo Branco, Escola Superior de Educação.

- FAUSTINO, A., MARIANO, Hugo, TEIXEIRA, Mara \& GOMES, Sara (2009). Caraterização da rotina diária de uma criança de 11 anos. Trabalho da Unidade Curricular de Desenvolvimento Motor. Castelo Branco, Escola Superior de Educação.

- FAUSTINO, A., MONTEIRO, Carlos \& GONÇALVES, Cedric (2009). Caraterização das rotinas de vida diária de uma criança de 8 anos. Trabalho da Unidade Curricular de Desenvolvimento Motor. Castelo Branco, Escola Superior de Educação. 
- FLICK, Uwe (2005). Métodos Qualitativos na Investigação Científica. Colecção: Manuais de Gestão. Tradução Artur M. Parreira. Lisboa, Monitor - Projectos e Edições, Lda.

- FORTIN, Marie-Fabienne (2000). Apresentação e interpretação dos resultados. In: Marie-Fabienne Fortin. 0 processo de investigação: da concepção à realização. Lusociência, Loures. 2. a. ed.: 329-338.

- FORTIN, Marie-Fabienne, BRISSON, Diane Prud'Homme \& COUTU-WAKULCZYK, Ginette (2000). Noções de ética em investigação. In: Marie-Fabienne Fortin. 0 processo de investigação: da concepção à realização. Lusociência, Loures. 2. ․ ed.: 113-130.

- FORTIN, Marie-Fabienne, CÔTÉ, José \& VISSANDJÉE, Bilkis (2000). A investigação científica. In: MarieFabienne Fortin. 0 processo de investigação: da concepção à realização. Lusociência, Loures. 2. ․ ed.: 15-24.

- FORTIN, Marie-Fabienne, GRENIER, Raymond \& NADEAU, Marcel (2000). Métodos de colheita de dados. In: Marie-Fabienne Fortin. 0 processo de investigação: da concepção à realização. Lusociência, Loures. 2. ${ }^{a}$ ed.: 239-265.

- GRAUE, M. Elisabeth \& WALSH, Daniel J. (2003). Investigação Etnográfica com Crianças: Teorias, Métodos e Ética. Tradução de Ana Maria Chaves. Lisboa, Fundação Calouste Gulbenkian.

- HASKELL, W., MONTOYE, H. \& ORENSTEIN, D. (1985). Physical activity and exercise to achieve health-related physical fitness components. Public Health Reports, 100: 202-212

- KIMCHI, J., POLIVKA, B. \& STEVENSON, J.S. (1991). Triangulation: operational definitions. Nursing Research, 40 (6): 364-366.

- LALANDA, Piedade (1998). Sobre a metodologia qualitativa na pesquisa sociológica. Análise Social, 33 (148): 871-883.

- MARCONI, Marina de Andrade \& LAKATOS, Eva Maria (1996). Técnicas de pesquisa. Atlas, São Paulo, 3. a ed.

- NETO, C. (1979). A Criança, o Espaço e Desenvolvimento Motor. Ludens, 3 (2/3), 35-44.

- NETO, C. (1994). A Família e a Institucionalização dos Tempos Livres. Ludens, 14 (1), 5-10.

- QUIVY, Raymond \& CAMPENHOUDT, Luc Van (1998). Manual de investigação em ciências sociais. Gradiva, Lisboa, 2. ${ }^{\mathrm{a}} \mathrm{ed}$.

- REIDY, Mary \& MERCIER, Louise (2000). A triangulação. In: Marie-Fabienne Fortin. 0 processo de investigação: da concepção à realização. Lusociência, Loures. 2.. ed.: 321-328.

- ROUSSEAU, Nicole \& SAILLANT, Francine (2000). Abordagem de investigação qualitativa. In: Marie-Fabienne Fortin. 0 processo de investigação: da concepção à realização. Lusociência, Loures. 2. ․ ed.: 147-160.

- SELLTIZ, JAHODA, DEUTSCH \& COOK (1974). Métodos de Pesquisa nas Relações Sociais. E.P.U., S. Paulo, 4. ${ }^{\text {a }}$ Ed.

- SERRANO, J. (1996). Envolvimento social e desenvolvimento da criança - Estudo das rotinas de vida diária das crianças com idades compreendidas entre os 7 e os 10 anos nos meios rural e urbano. Monografia apresentada com vista ao grau de Mestre. Universidade Técnica de Lisboa - F.M.H.

- TRIVIÑOS, Augusto Nibaldo Silva (1992). Introdução à pesquisa em ciências sociais: a pesquisa qualitativa em educação. Atlas, São Paulo, 3.. ed.

- VALA (1986). Análise de Conteúdo. In: Metodologia das Ciências Sociais. Afrontamento, Porto: 101-128. 
